European Polymer Journal

June 2015, Volume 67 Pages 326-334

http://dx.doi.org/10.1016/i.eurpolymi.2015.04.015

http://archimer.ifremer.fr/doc/00260/37148/

(c) 2015 Elsevier Ltd. All rights reserved.

\title{
Water diffusivity in PA66: Experimental characterization and modeling based on free volume theory
}

\author{
Broudin M. ${ }^{1}$, Le Gac Pierre-Yves ${ }^{2,{ }^{*}}$, Le Saux V. ${ }^{3}$, Champy C. ${ }^{1}$, Robert G. ${ }^{4}$, Charrier P. ${ }^{1}$, Marco Y. ${ }^{3}$ \\ ${ }^{1}$ TrelleborgVibracoustic, Z.I. Nantes Carquefou, BP 419, 44474 Carquefou Cedex, France \\ 2 IFREMER, Marine Structures Laboratory, Centre de Brest, BP 70, 29280 Plouzané, France \\ ${ }^{3}$ Laboratoire Brestois de Mécanique et des Systèmes (EA 4325), ENSTA Bretagne/Université de \\ Brest/ENIB, 2 rue F. Verny, 29806 Brest Cedex 9, France \\ ${ }^{4}$ Solvay Engineering Plastics, Technyl Innovation Center-Simulation et Validation des Applications, \\ Avenue Ramboz, BP 64, 69192 Saint Fons, France \\ * Corresponding author : Pierre-Yves Le Gac, Tel.: +33 02982248 85; fax: +33 0298224535 ; email \\ address : pierre.yves.le.gac@ifremer.fr
}

\begin{abstract}
:
Diffusion of water in polyamide 6.6 has been characterized for a wide range of temperatures (from 25 to $80^{\circ} \mathrm{C}$ ) and various humidities using dynamic vapor sorption machine. The decrease in glass transition temperature $(\mathrm{Tg})$ has also been measured using DMA tests. As usually observed, PA66 absorbs a large amount of water (up to $5 \%$ at $90 \% \mathrm{RH}$ ) with a Fickian behavior with a diffusion coefficient that depends on water activity for all temperatures. Moreover, it appears that the diffusion coefficient for tests performed below $\mathrm{Tg}$ is almost independent of the water activity whereas a strong dependency is observed above Tg. This behavior is to be compared to a large decrease of $\mathrm{Tg}$ with the absorption of water. The increase of the water diffusion can therefore be related to a change of the amorphous phase (the crystalline phase is supposed to absorb no water) from the glassy to the rubbery states. A model based on the free volume theory is used successfully to describe the wide experimental database. It is therefore possible to describe the dependency of the water diffusion kinetics on both temperature and water uptake using the approach described in this paper.
\end{abstract}




\section{Graphical abstract}

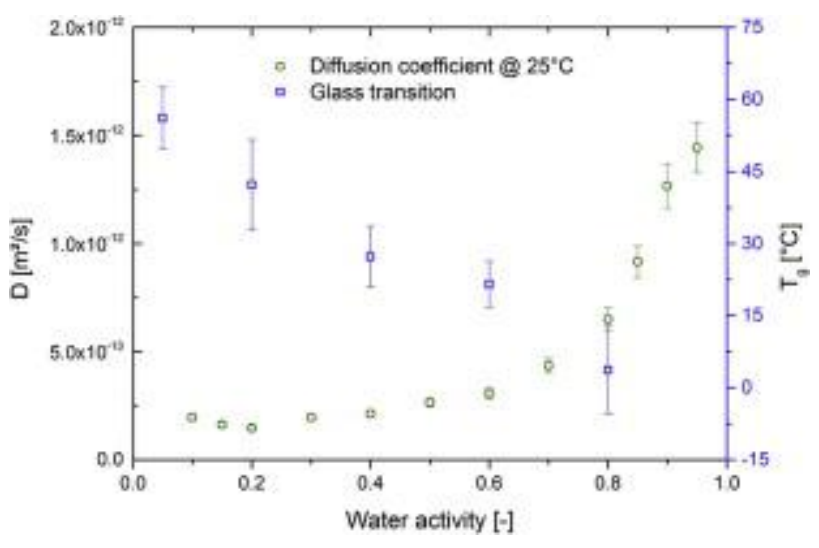

\section{Highlights}

- The paper presents original water absorption results for polyamide 6.6. An important influence of water activity on water diffusion kinetic is observed when amorphous phase is in rubbery state. The influence of water activity on diffusivity can be predicted based on physical consideration, i.e. the free volume theory.

Keywords : Water absorption, Free volume, Polyamide, Modeling 


\section{Introduction}

Water diffusion in polymers has been widely investigated in the literature over the last 50 years in order to establish the diffusion mechanisms, to consider the physical consequences of water sorption and to evaluate the water diffusion rate. Water diffusion mechanisms are still controversial. Water absorption in a polymer has been linked to free volume [1][2], to formation of hydrogen bonds between water and the polymer [3][4] or to cluster formation [5][6][7][8].

The consequences of water sorption on properties are better known. The presence of water in a polymer can lead to two different types of degradation. The first one is reversible and is due to an increase of the chain mobility induced by water sorption; this type of degradation usually leads to a decrease of the elastic modulus and an increase of the elongation at break. The second one is irreversible and the best-known is the hydrolysis of the polymer that leads to chain scission in the polymer network and to a dramatic decrease of the mechanical properties [9]. Other degradation such as differential swelling or additive leaching may also occur. Both reversible and irreversible degradations depend on water absorption rate, i.e. the rate at which water diffuses from the external medium or atmosphere into the polymer.

Water diffusion in polyamide 6,6 (PA66) has been considered many times in the literature, which could probably be explained by the fact that PA66 absorbs a large amount of water, for example, Lim et al. [10] found that PA66 absorbs up to $8.5 \%$ when immersed in water at $23^{\circ} \mathrm{C}$. Moreover, as for all semi crystalline polymers, water is absorbed only in the amorphous phase (approximately 65\% depending on process parameters) leading to even higher water absorption for lower crystallinity ratios [11]. This large water absorption could be attributed to the chemistry of the polymer, as the presence of amide bond leads to high hydrophilicity of this polymer [12][13][14].

The presence of water in the amorphous phase of PA6.6 leads to a large increase in terms of chain mobility and so to a large decrease of glass transition temperature $\left(T_{g}\right)[15]$. For example, Lim et al. [10] found that the $T_{g}$ of PA6.6 can decrease with water absorption from $60^{\circ} \mathrm{C}$ (in the dry state) to $-10^{\circ} \mathrm{C}$. As evoked previously in the general case, this large increase of mobility leads to a modification of the mechanical behavior with a decrease of the material stiffness [16] and an increase in the elongation at break [17]. Moreover because of the large change in $\mathrm{T}_{\mathrm{g}}$ with water absorption, the state of the amorphous phase of the polymer can evolve if $\mathrm{T}_{\mathrm{g}}$ becomes lower than the service (or testing) temperature. Water diffusion in this case is known as a -ase II" diffusion that was first described by Alfrey et al. [18] and explored in detail by Thomas and Windle [19]. This -ease II" analysis is based on the fact that water diffusion rates in the polymer are much lower in the glassy state than in the rubbery state. When the amorphous phase is in a rubbery state, the water absorption in PA6.6 depends not only on temperature but also on water activity in the external environment, as already described in the literature for many polymers [19][20]. This behavior could be explained according to the free volume theory that considers an increase of the polymer volume due to hole creation when the polymer is above its $T_{g}$, leading to a large modification of the polymer/water interactions and therefore of the water diffusion rate. This mechanism has been characterized recently for polyamide 6 by Dlubek et al. [21]. From a 
modeling point of view, Vrentas and Duda, expressed the water diffusion coefficient changes with free volume and temperature for a general case [22].

When exposed to water at high temperature or for long duration, amide bonds can undergo hydrolysis [23][24]. This chemical degradation leads to a reduction of molecular weight in the amorphous phase and to a large decrease in mechanical properties [25][26]. This irreversible degradation will not be considered in this study, testing temperature and time will be low enough to avoid this kind of degradation [15].

The objective of this study are both to characterize properly water diffusivity in PA66 with special attention paid to both temperature and water activity and to challenge a model of water absorption using the free volume theory. First, a reliable experimental database characterizing the water diffusion in PA66 for a wide range of temperature and humidity is presented. Both maximal water absorption and water diffusion rate were considered but special attention has been paid to the understanding and the description of the dependencies of water diffusion rate on water activity and temperature. Furthermore, in order to challenge the water absorption modeling based on free volume, the change in the glass transition temperature $\left(\mathrm{T}_{\mathrm{g}}\right)$ has been measured using DMA tests, for the same sample geometry. As a preliminary step, the change in $T_{g}$ according to the water uptake is compared to the literature data and modeling. Then, modeling of water diffusion rate is considered. The low variation of the water diffusivity with the water activity below the $T_{g}$ is checked and a classical temperature effect is identified. Then, the validity of the model suggested by Vrentas and Duda [22] above $T_{g}$ is tested on the experimental data, using values from the literature.

2. Material and Method

\subsection{Material}

The material studied is a polyamide 6.6 provided by Solvay ${ }^{\circledR}(\mathrm{A} 218$ nat) with a density of $1140 \mathrm{~kg} . \mathrm{cm}^{-3}$, and a number average molecular weight of $16.5 \mathrm{~kg} / \mathrm{mol}$. Films of $100 \mu \mathrm{m}$ thickness were cut from injected samples (with an injected thickness of $5 \mathrm{~mm}$ ) with a Leica microtome, no visual damage was observed on the sample surface. The glass transition temperature of the polymer in the dry state is $58 \pm 2^{\circ} \mathrm{C}$ measured by dynamical mechanical analysis (DMA). Crystallinity has been measured using DSC (Q200 from TA Instruments) with a heating rate of $10^{\circ} \mathrm{C} / \mathrm{min}$ and a theoretical value of $188.4 \mathrm{~J} / \mathrm{g}$ for the calculation [27], the crystallinity ratio is equal to 0.35 .

\subsection{Water uptake}

Water absorption characterizations were performed using a Q5000SA Dynamic Vapor Sorption (DVS) from TA Instruments ${ }^{\mathrm{TM}}$. This machine is dedicated to monitoring water uptake using a microbalance with a $0.1 \mu \mathrm{g}$ resolution placed in a humidity chamber that controls both temperature (from 5 to $80^{\circ} \mathrm{C}$ ) and water activity (from 0 to 1 ).

Thin films were placed inside the machine and dried at testing temperature, until equilibrium was reached. Water activity in the humidity chamber was then increased by steps of 0.1 , this activity was controlled by mixing a dry nitrogen flow with a wet nitrogen flow at $200 \mathrm{ml} / \mathrm{min}$. Changes in mass are recorded with a frequency of about $0.1 \mathrm{~Hz}$ in order to be able to follow the water absorption $M_{t}$, defined as follows: 


$$
M_{t}=\frac{m_{t}-m_{0}}{m_{0}} \times 100
$$

where $m_{t}$ is the mass of the sample at time $t$ and $m_{0}$ is the mass of the sample in the dry state. Figure 2a shows an example of a DVS measurement.

Polyamide is a semi-crystalline polymer and as water diffuses only in the amorphous phase [12][14], the water content in the amorphous phase will be considered in this paper. The relative mass ratio $w_{\mathrm{H}_{2} \mathrm{O}}$ and relative volume ratio $v_{\mathrm{H}_{2} \mathrm{O}}$ are therefore considered and defined as:

$$
\begin{gathered}
w_{\mathrm{H}_{2} \mathrm{O}}=\frac{\Delta m}{(1-\chi) m_{0}+\Delta m} \\
v_{\mathrm{H}_{2} \mathrm{O}}=\frac{w_{\mathrm{H}_{2} \mathrm{O}} \rho_{\mathrm{a}}}{w_{\mathrm{H}_{2} \mathrm{O}} \rho_{\mathrm{a}}+\left(1-w_{\mathrm{H}_{2} \mathrm{O}}\right) \rho_{w}}
\end{gathered}
$$

where $\rho_{a}$ and $\rho_{w}$ are the respective densities of the amorphous phase of the polymer and water. Their values will be taken equal to $1080 \mathrm{~kg} \cdot \mathrm{m}^{-3}$ for $\rho_{a}$ [28] and 1000 kg. $\mathrm{m}^{-3}$ for $\rho_{w} \cdot \chi$ is the crystallinity ratio. Water absorption is considered here at the scale of the films i.e. 100 micrometers and therefore the distribution of water in the amorphous phase is considered homogeneous, even if some recent studies have shown that some heterogeneities could occur at a macromolecular scale [29][30].

We focus here only on the beginning of the sorption curve. If during this limited duration the diffusion kinetics obey to a law writing as follows:

$$
\frac{\partial C}{\partial t}=D \frac{\partial^{2} C}{\partial x^{2}}
$$

Then, without assuming the evolution of the concentration for longer durations, the water diffusion coefficient in a semi infinite plate in one dimension can be written according to [31]:

$$
\frac{M_{t}}{M_{\infty}}=\frac{4}{e} \sqrt{\frac{D \cdot t}{\pi}}
$$

where $M_{t}$ and $M_{\infty}$ are the amounts of moisture absorbed at time $t$ and at equilibrium, respectively, and $e$ is the thickness of the film samples. Equation 5 is suitable only for $0 \leq \frac{M_{t}}{M_{\infty}} \leq 0,5$. This equation (5) is used here to determine a water diffusion coefficient, assuming that the variation, of $\mathrm{D}$ along the characterization step is negligible. This is only valid because experiments have been performed using small steps in activity. This equation cannot be used if large variation of $D$ occurs during testing due to the water uptake. For each step, the water uptake was then modeled using the $D$ value determined using Equation 5 in 
order to check that Fickian behavior can be used to describe the water absorption (the $\mathrm{R}^{2}$ value was above 0.98 for all tests).

\subsection{Glass Transition Measurement}

Glass Transition temperature measurements were performed using a Dynamic Mechanical Analyser on films on a Metravib ${ }^{\mathrm{TM}} \mathrm{DMA}^{+} 150$ machine controlled with the Dynatest software. Samples were $100 \mu \mathrm{m}$ films tested in tensile mode with a dynamic displacement of $1.10^{-5} \mathrm{~m}$ at a frequency of $1 \mathrm{~Hz}$. Temperature was increased at a rate of $1{ }^{\circ} \mathrm{C} / \mathrm{min}$ and $\mathrm{T}_{\mathrm{g}}$ was determined from the inflection of the drop of the storage modulus. In order to study the effect of water content on $T_{g}$ as shown in Figure 1, samples were fully saturated for different water activities before each test using a thermo-hygrometric device (SERVATHIN B204 3235). Water desorption during testing was considered to be negligible due to the long time of desorption compared to the DMA testing time. To assess this assumption, the sorption/desorption times have to be compared to the testing duration. The worst cases are encountered for the extreme humidity ratios because on the one hand a low humidity ratio means a high $\mathrm{T}_{\mathrm{g}}$ and therefore a high maximum testing temperature and on the other hand, a high humidity ratio means a high value of the diffusion coefficient. An evaluation for both cases considering the maximum tested temperature during the test (conservative case), led to sorption/desorption times of 200 and 160 minutes, respectively, that are well above the testing duration of 30 minutes. In order to provide another evaluation of the change in $T_{g}$, DSC data from [10] are also plotted in Figure 6. The two evaluations seem to be consistent despite the use of different techniques. For each condition, three samples were tested and the results averaged.

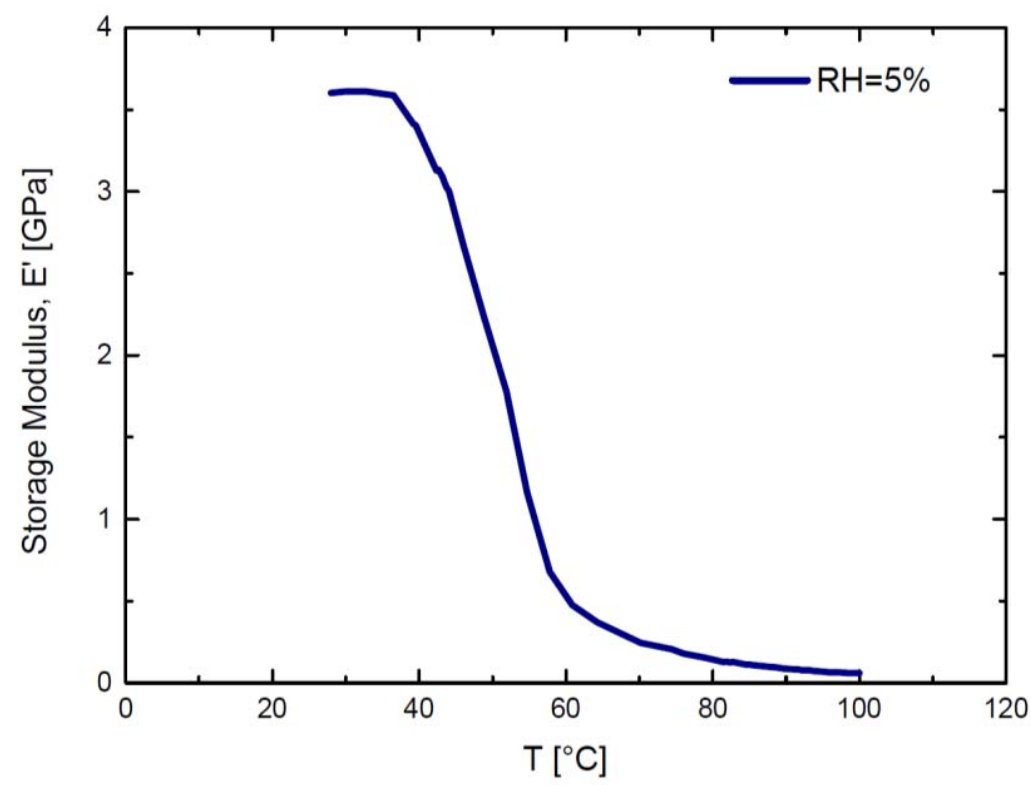

Figure 1: $\mathrm{T}_{\mathrm{g}}$ measurement using DMA on a film that has been saturated at $5 \% \mathrm{RH}$

3. Results

Dynamic vapor sorption was used to characterize water sorption in PA66 and the effects of temperature and humidity on the water absorption behavior. Figure $2 a$ presents a typical change in mass at $40^{\circ} \mathrm{C}$ for several water activities for a thin film. For each water 
activity step, the water absorption curve is considered (as example is shown in Figure $2 b$ ). From this curve it appears that water absorption in PA66 films exhibits a Fickian behavior because small steps in water activity have been used. At the early stage of water absorption, normalized mass uptake is directly proportional to square root of time divided by the sample thickness. Then water absorption reaches a plateau. These observations are true for all the conditions considered in this study. The water absorption in PA66 can therefore be defined by two characteristics:

- Maximum water uptake, i.e. water solubility in the polymer and,

- Diffusion coefficient $D$, i.e. kinetics of water absorption.

These two parameters and their variations with temperature and water activity will be described in the next sections.

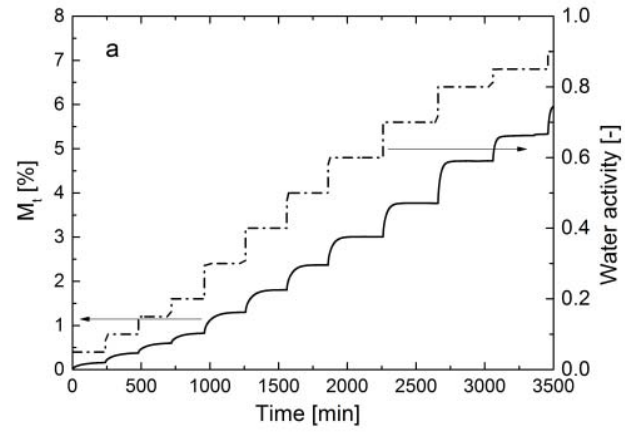

Figure 2a: Example of DVS measurement for $\mathrm{T}=40^{\circ} \mathrm{C}$

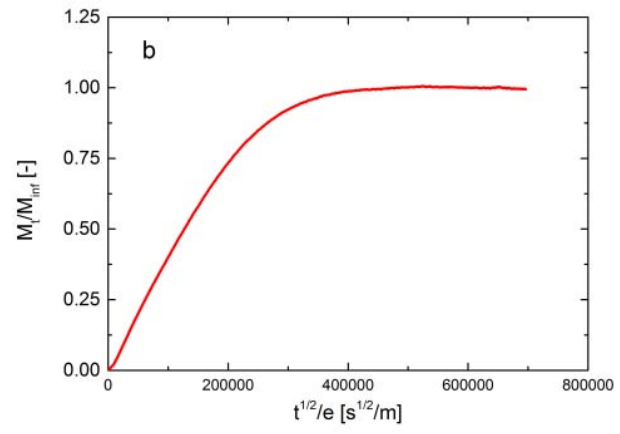

Figure $2 \mathrm{~b}$ : Sorption for $\mathrm{T}=60^{\circ} \mathrm{C} / \mathrm{RH}=60 \%$

\subsection{Saturation moisture content}

The maximum water absorption is linked to the water solubility in the polymer that depends on the chemical nature of the polymer [10][32][33]. Classically for PA66, a large water uptake is observed. Moreover the dependency of the water uptake on the activity for a given temperature is not linear. This means that PA66 does not follow Henry's law (Figure 3 ). For high water activities a deviation towards higher water uptake appears due to water clustering in the polymer [10][13][20]. The origin of clustering in polyamide is attributed to the formation of hydrogen bonds between water molecules, this phenomenon can be described conveniently using Equation 6 [34]:

$$
v_{\mathrm{H}_{2} \mathrm{O}}=H \cdot a+b \cdot a^{m}
$$


where $v_{\mathrm{H}_{2} \mathrm{O}}$ is the volume fraction of water, $a$ is the water activity in an environment and $\mathrm{H}$, $b$ and $m$ are polymer characteristics.

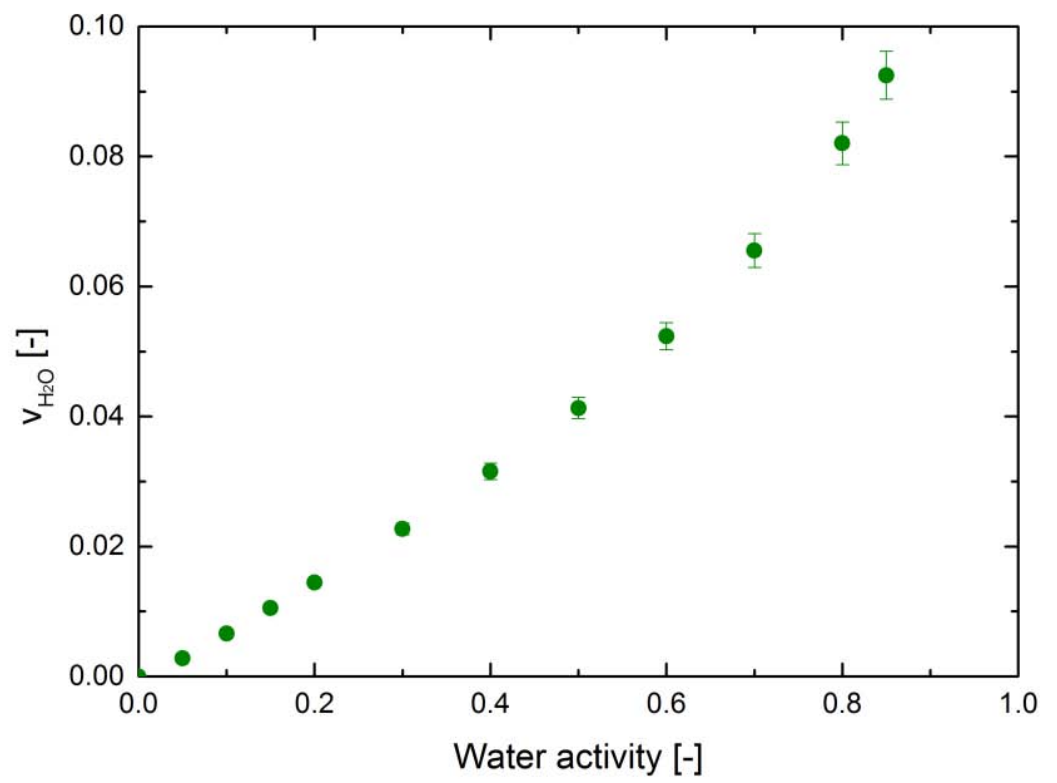

This

Figure 3: Change in volumic water content in the amorphous part in PA66 with water activity at $40^{\circ} \mathrm{C}$

clustering behavior is observed for all the investigated temperatures.

In a companion paper [35] it has been shown that the temperature dependency of the solubility can be taken into account in Equation 6, while parameters $b$ and $m$ are kept independent from the temperature.

$$
S=S_{0} \cdot \exp \left(\frac{-H}{R T}\right)
$$

In Equation 7, $S$ is the water solubility in the Henry term, $S_{0}$ is the pre-exponential factor and is equal to $1.95 .10^{-2}, H$ is the enthalpy, $R$ is the perfect gas constant and $T$ the absolute temperature. The value of $-3 \mathrm{KJ} / \mathrm{mol}$ is related to the enthalpy, this value is in accordance with published values and explained in detail in [15].These parameters have been determined based on moisture absorption at several temperatures, for more details see [35].

\subsection{Water diffusion kinetics}

\subsubsection{Influence of the water activity}

In the case of PA6.6, the water diffusion rate depends on the water activity in the external environment at a given temperature. The strong dependency of diffusion kinetics on water activity is illustrated here for a temperature of $25^{\circ} \mathrm{C}$ (see Figure 4) but this dependency on the water activity has been observed for all tested temperatures. In the case presented, the water diffusion coefficient for an activity of 0.9 is about 10 times higher than for an activity of 0.2 . Furthermore, the variation in $\mathrm{D}$ with the water activity is not simple: for a water activity lower than 0.4 , the water diffusion coefficient is almost constant (an increase of about $50 \%$ is 
observed) whereas for a water activity higher than 0.6 , the water diffusion coefficients increase significantly (by a factor 5 ) with activity. This will be discussed in the following on the basis of the change in $T_{g}$ with water content in the polymer.

\subsubsection{Influence of the temperature}

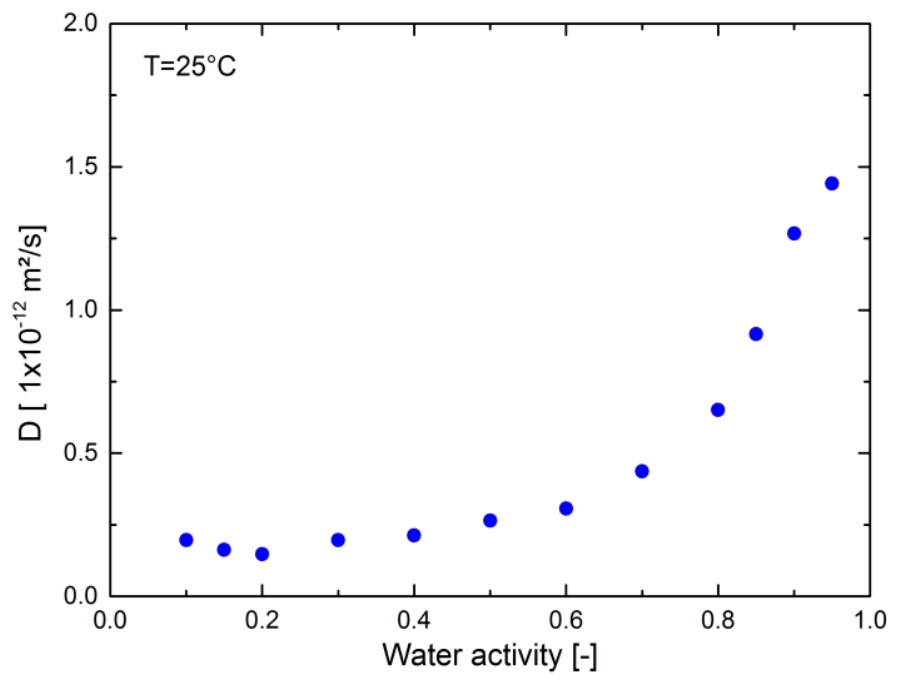

Figure 4 : Water diffusion measured at $25^{\circ} \mathrm{C}$ for different activities

As temperature increases mobility, water diffusion in PA66 is logically increased. Nevertheless, the effect of water activity on the diffusion coefficient is not the same for all temperatures. When the testing temperatures are above the $T_{g}$ of the polymer in a dry state (i.e. 60,70 and $80^{\circ} \mathrm{C}$ in Figure 5), a monotonic increase of $\mathrm{D}$ with water activity is observed, whereas when the testing temperatures are below the $T_{g}$ of the polymer in a dry state (i.e. $25^{\circ} \mathrm{C}$ in figure 4 and $40^{\circ} \mathrm{C}$ in figure $5 \mathrm{a}$ ), a more complex variation is observed with a plateau for low activities and then an increase of $D$ for higher activities. This dual mode can be explained by a change of the state of the amorphous phase during the test due to a decrease of the $\mathrm{T}_{\mathrm{g}}$ induced by the sorption of water in the polymer. In order to assess this interpretation, the next section investigates the variation of $T_{g}$ with water absorption. We notice that at $25^{\circ} \mathrm{C}$ a plateau for water diffusivity can be observed at high humidity level (figure 4) , the origin of this plateau is not clear and would merit further investigation.
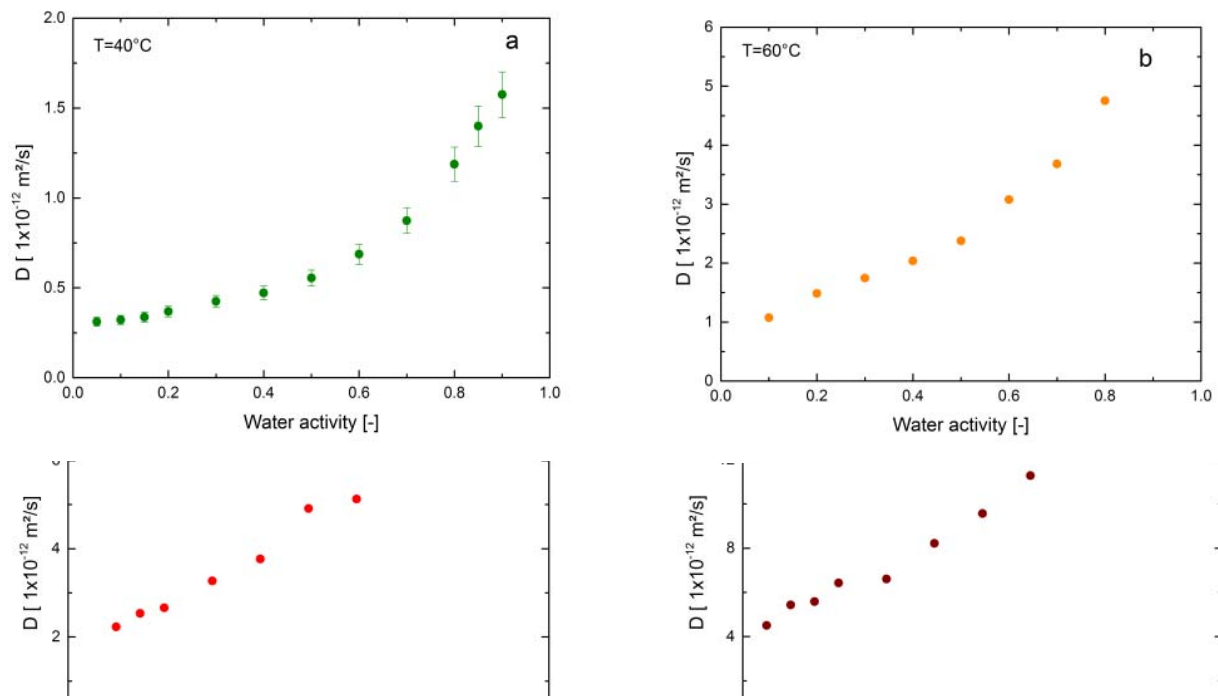


\subsection{3 $\mathrm{T}_{\mathrm{g}}$ variation with water absorption}

The presence of water in a polymer can lead to an increase of the chains mobility due to the so-called plasticization phenomenon [10]. In order to investigate this phenomenon for PA66, the glass transition temperature has been characterized on films saturated with different water contents; results are plotted in Figure 6. It can be observed that the water absorption leads to a large decrease of the $\mathrm{T}_{\mathrm{g}}$ from $55^{\circ} \mathrm{C}$ for a humidity ratio of $5 \%$ to $0^{\circ} \mathrm{C}$ for a sample exposed to a humidity of $80 \%$. This decrease in $\mathrm{T}_{g}$ with water absorption is in accordance with existing results [10][15][36].

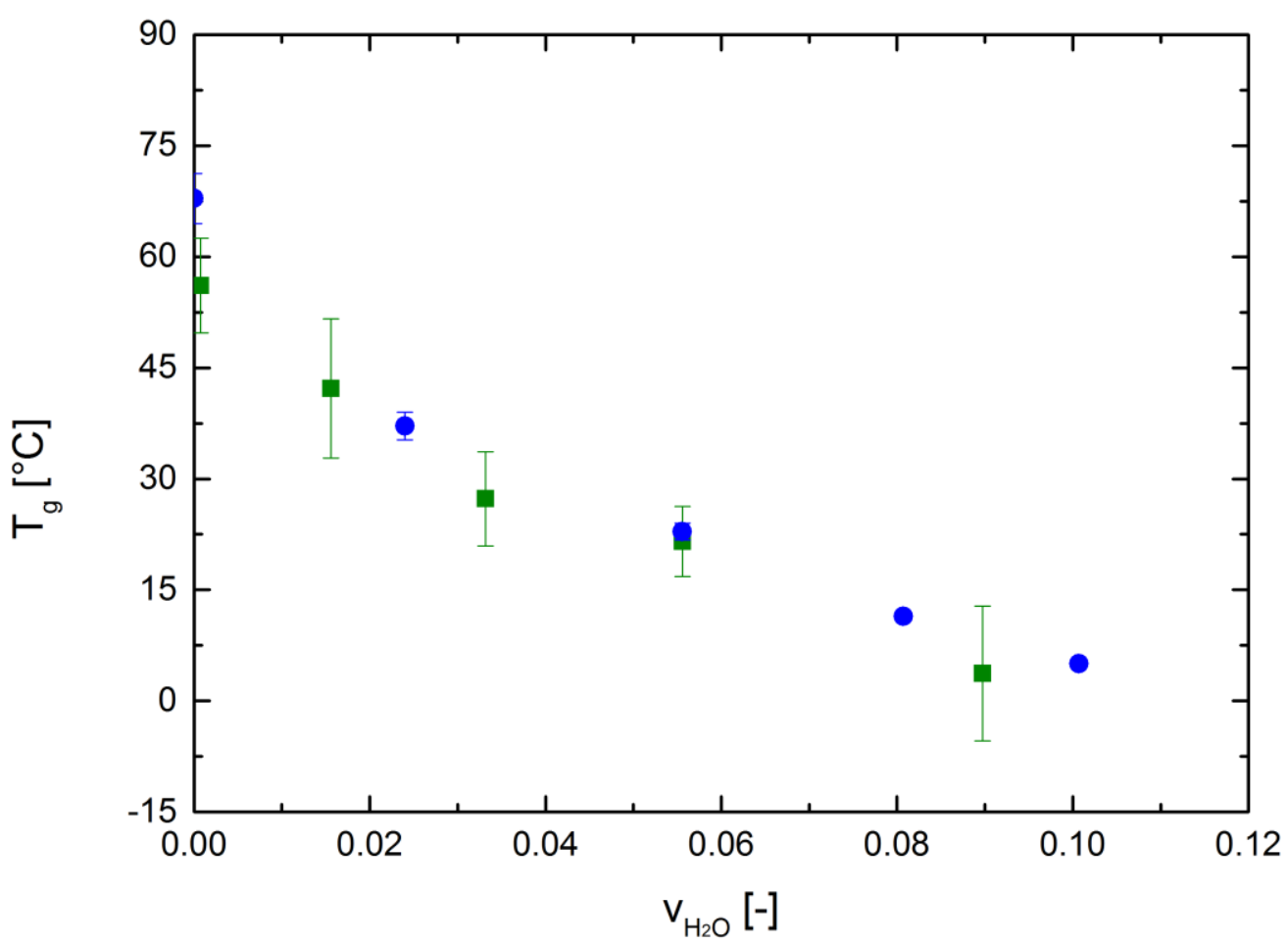

Figure 6: Effect of the water content in the amorphous phase of PA66 on $\mathrm{T}_{\mathrm{g}}$

4. Discussion and modeling approach to describe the diffusion coefficient

The experimental data presented in the previous section, obtained for wide ranges of temperatures and water activities, illustrated that diffusion of water in PA66 exhibits a complex behavior, depending both on temperature and water activity. As polyamide 
hydrolysis does not occur in the time of testing in this study there is only a reversible degradation of the polymer [15].

The previous section also illustrated that as PA66 absorbs water from the environment a decrease of the glass temperature transition occurs, very likely induced by an increase of the molecular chain mobility. This $T_{g}$ variation induces a change of the amorphous phase in the polymer from the glassy to the rubbery state and consequently to a modification of the absorption behavior [10][15][20]. Figure 7 illustrates well what happens: as long as $T_{g}$ is above the testing temperature $\left(25^{\circ} \mathrm{C}\right.$ for the test presented) the amorphous phase of the polymer is in glassy state and the water diffusion coefficient is almost constant. When water absorption is high enough to decrease the glass transition temperature below the testing temperature $(a=0.6$ in Figure 7$)$, the amorphous phase is then in a rubbery state and the water diffusion coefficient increases significantly with the water activity. This behavior has already been observed for epoxy resins [37][38] or PHEMA [20][39].

The question here is how to describe such behavior based on physical considerations? We will first focus on the prediction of $T_{g}$ variation with water absorption, then water diffusion coefficient when the polymer is in the glassy state and finally a modeling of water diffusivity when PA66 is in the rubbery state.

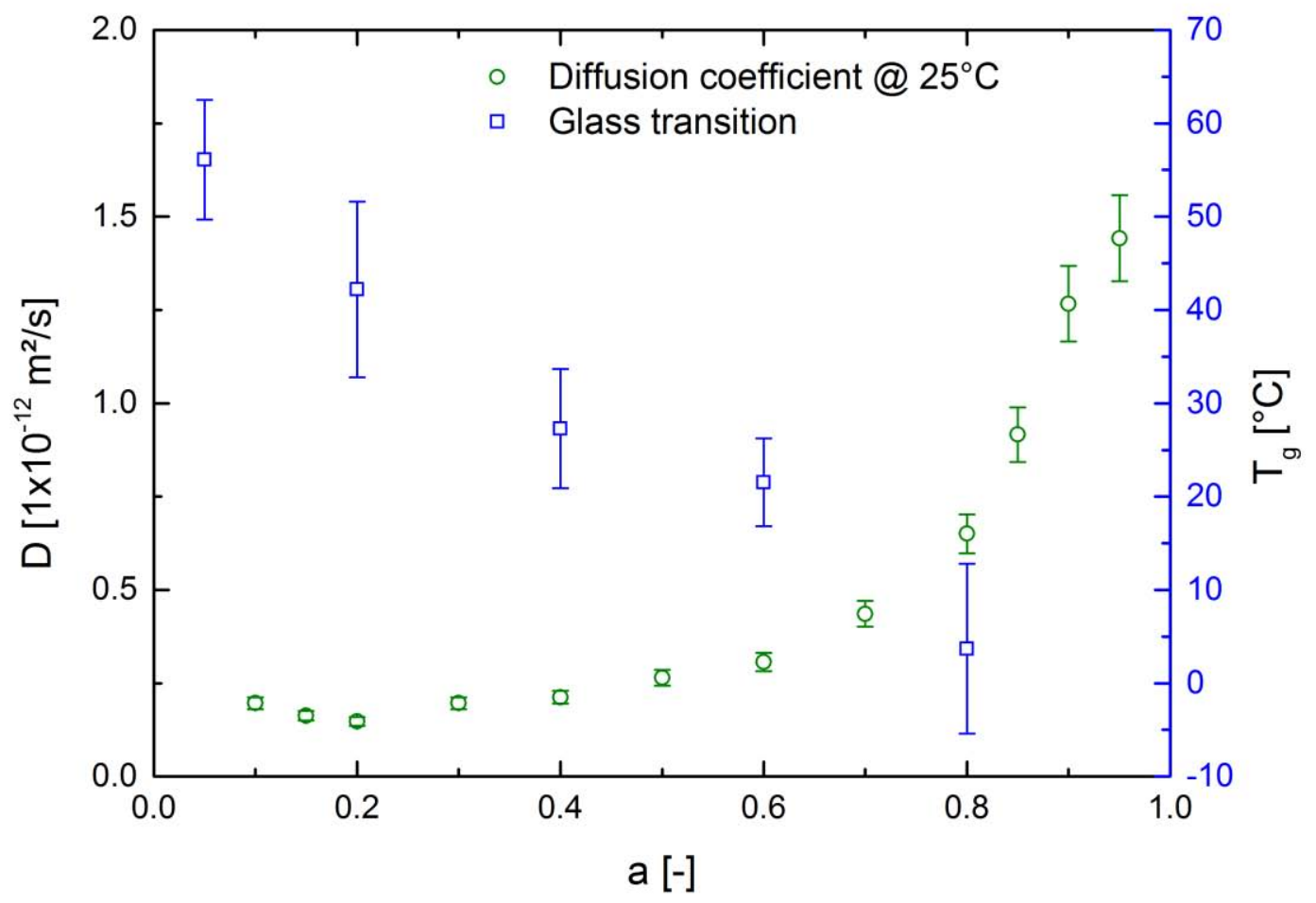

Figure 7: Water activity effect on both $\mathrm{Tg}$ and water diffusion coefficient at $25^{\circ} \mathrm{C}$

\subsection{Determination of the water diffusion coefficient in PA66}

\subsubsection{Prediction of $\mathrm{T}_{\mathrm{g}}$}


Because the water absorption behavior depends on the state of the amorphous phase of PA66, the first step of the approach is to determine how the value of $T_{g}$ depends on the water uptake. The amount of water in the polymer is here measured for every tested condition but could also be evaluated directly from the environmental conditions using Equations 6 and 7, as described in more details in [34][35].

This glass transition temperature decrease with the amount of water in the polymer can be evaluated using the Kelley-Bueche equation simplified using the Simha-Boyer rule [15] (Equation 8):

$$
\frac{1}{T_{g}}=\frac{1}{T_{g p}}+A \cdot v_{H_{2} \mathrm{O}} \quad \text { with }: \quad A=\frac{1}{T_{g s}}-\frac{1}{T_{g p}}
$$

where $T_{g}$ is the actual glass transition temperature of the polymer $(\mathrm{K}), T_{g p}$ is the polymer glass transition temperature in the dry state (333K according to [10]), $T_{g s}$ is the glass transition of solvent (here water) that is taken equal to $110 \mathrm{~K}$ [40] and $v_{\mathrm{H}_{2} \mathrm{O}}$ is the volume fraction of water in the polymer.

Figure 8 presents the comparison of the experimental data to the prediction of $T_{g}$ using the Kelley-Bueche relation and illustrates that a good agreement is obtained.

Knowing the environmental conditions, it is therefore possible to evaluate the water content of the amorphous phase and then, using the Kelley-Bueche equation, it is possible to predict the $T_{g}$ of the polymer. The comparison of the environment temperature to the $T_{g}$ allows finally the state of the amorphous phase in PA66 to be determined. The next step is to evaluate the water diffusion coefficient for these two specific conditions: glassy and rubbery states. 


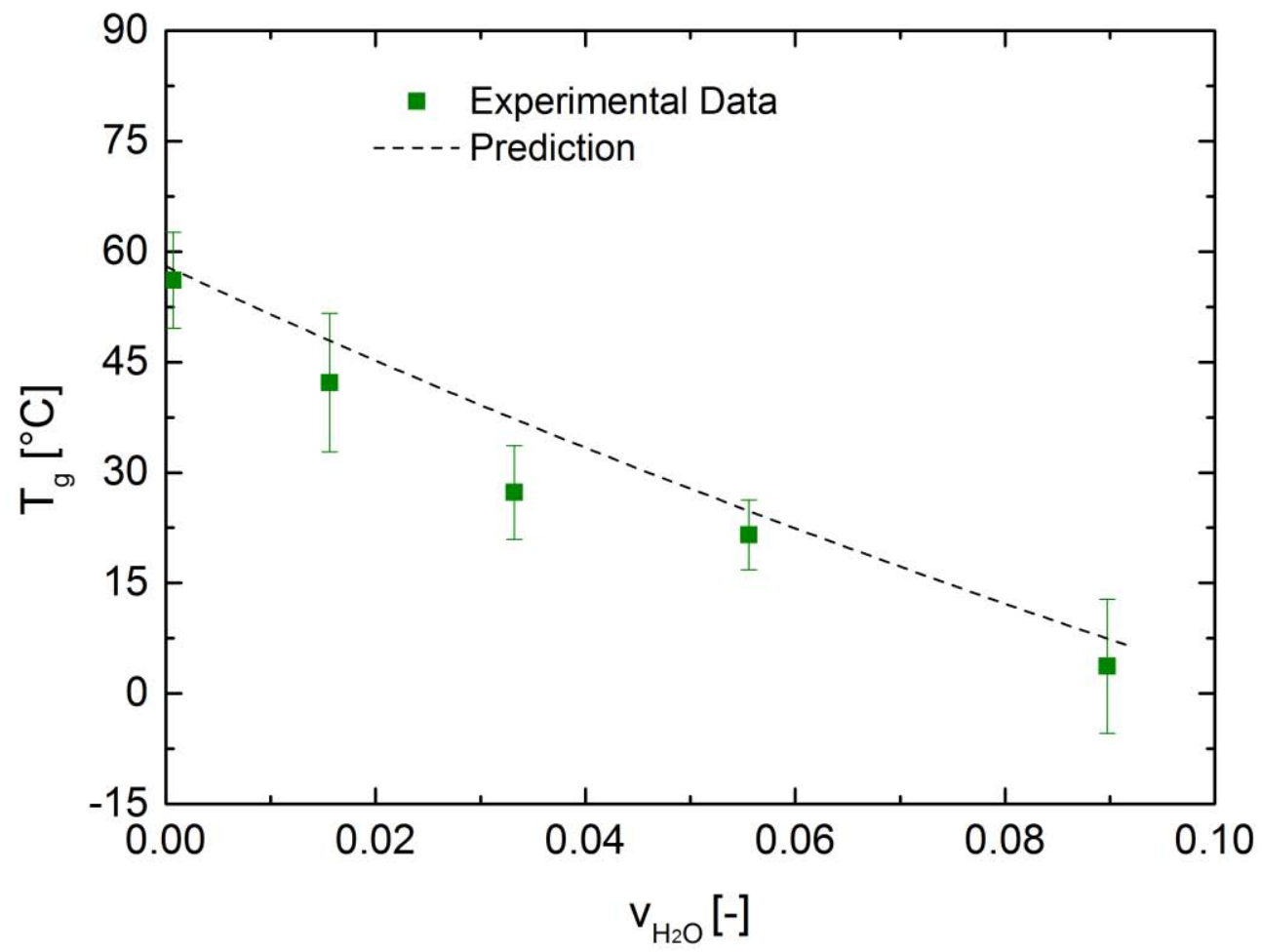

Figure 8: $\mathrm{T}_{\mathrm{g}}$ decrease with volumic water content in PA66, comparison between experimental data and prediction

\subsubsection{Water absorption in the case of a glassy state}

The experimental data obtained showed that the water absorption in PA66, when the testing temperature remains below $T_{g}$, is sensitive only to the environment temperature and not (or only slightly) to the water activity. In this case, a simple model (Equation 9) can be suggested and Figure 9 shows that the effect of temperature on the water diffusion coefficient can be described using a typical Arrhenius behavior according to:

$$
D_{\left(T<T_{g}\right)}=D_{01} \cdot \exp \left(\frac{-E_{a}}{R T}\right)
$$

where $D\left(T<T_{g}\right)$ is water diffusion when PA66 is in the glassy state $\left(\mathrm{m}^{2} / \mathrm{s}\right) ; D_{01}$ is a preexponential factor and equals $9.10^{-10} \mathrm{~m}^{2} / \mathrm{s}, R$ is the perfect gas constant, $T$ is the absolute temperature $(\mathrm{K})$ and $E_{a}$ is the activation energy in the glassy state, and is equal to $20 \mathrm{~kJ} / \mathrm{mol}$.

The activation energy is relatively low compared to published values available for other polymers, this behavior could be related to the low activation energy of the $\beta$ transition measured at $25 \mathrm{~kJ} / \mathrm{mol}$ (data not shown here) or the hydrogen bond energy between amide and water. 


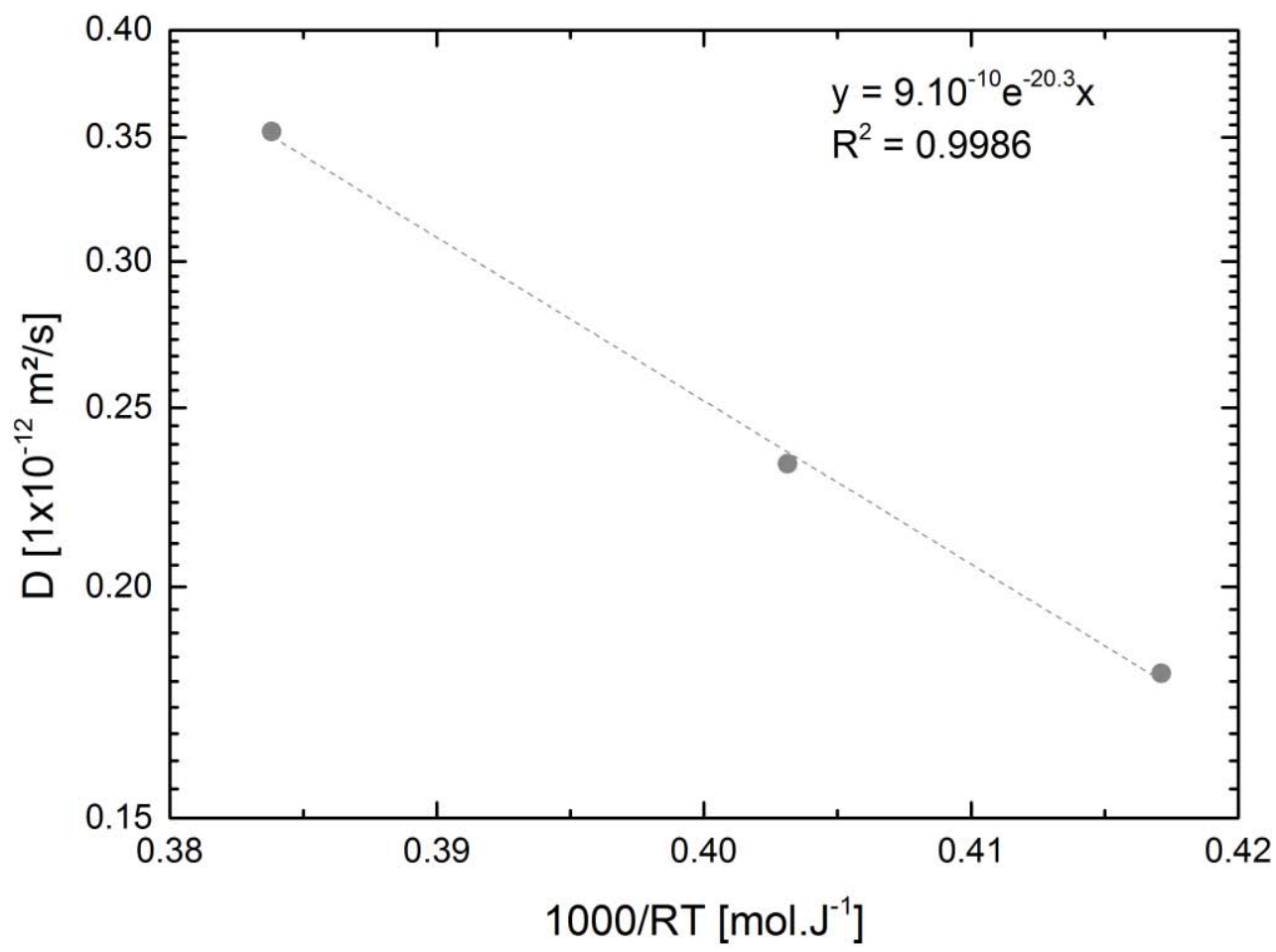

Figure 9: Temperature effect on water diffusion coefficient when PA66 is in the glassy state

It is consequently possible to describe the temperature dependence of water diffusion in PA66 when the material is in the glassy state using an Arrhenius behavior. This approach has been developed many times previously [38][41][42][43].

\subsubsection{Water absorption in the case of a rubbery state}

When PA66 is in a rubbery state, the water diffusion coefficient depends both on temperature and water activity. This could be explained according to the free volume theory, that basically considers an increase of the polymer volume due to hole formation when the polymer is above its $T_{g}$. This leads to a large modification of the polymer/water interactions and of the water diffusion. According to Vrentas and Duda [22] and based on work of Cohen and Grest [28], the water diffusion coefficient is related to free volume in the polymer according to Equation 10:

$$
D_{(T>T g)}=D_{02} \cdot \exp \left(-\frac{\gamma \cdot\left(w_{1} \cdot \hat{V}_{1}^{*}+\xi \cdot w_{2} \cdot \hat{V}_{2}^{*}\right)}{\hat{V}_{F H}}\right) \cdot \exp \left(-\frac{E}{R T}\right)
$$

With:

$$
\frac{\hat{V}_{F H}}{\gamma}=\left(\frac{K_{11}}{\gamma}\right) \cdot w_{1} \cdot\left(K_{21}+T-T_{g 1}\right)+\left(\frac{K_{12}}{\gamma}\right) \cdot w_{2}\left(K_{22}+T-T_{g 2}\right)
$$


where $D$ is the water diffusion coefficient $\left(\mathrm{m}^{2} / \mathrm{s}\right), D_{02}$ is a pre-exponential factor $\left(\mathrm{m}^{2} / \mathrm{s}\right)$ and is related to the friction coefficients between the solvent and the polymer and is dependent on the molecular weight and on the polymer and the solvent [22][44], $\hat{V}_{1}^{*}$ is the critical local hole free volume required for a molecule of species 1 (here water) to jump to a new position, $\hat{V}_{2}^{*}$ is the critical local hole free volume per gram of polymer required for the displacement of a jumping unit. The effect of this value on the diffusivity prediction has already been described in (Hong, 1995), it appears that $\hat{V}_{2}^{*}$ could affect largely the value of $D$ especially for low solvent content. Furthermore, $w_{1}$ is the relative mass ratio of component 1 (here water) i.e. $w_{\mathrm{H} 2 \mathrm{O}}$ in $\mathrm{Eq} 2, w_{2}$ is the relative mass ratio of component 2 (here the polymer) and equal to $1-w_{1}, \xi$ is the ratio of the critical molar volume of the solvent jumping unit to the critical molar volume of the polymer jumping unit, $\gamma$ is an overlap factor (which should be between 0.5 and 1 ) introduced because the same free volume is available to more than one molecule. $E$ is the energy per mole that a molecule needs to overcome attractive forces holding it to its neighbors. $\hat{V}_{F H}$ is the average hole free volume per gram of mixture and can be calculated with Equation 10 where $K_{11}$ and $K_{21}$ are free volume parameters for the solvent, here water, and $K_{12}$ and $K_{22}$ are free volume parameters for the polymer, $T_{g 1}$ is glass transition temperature of water, $T_{g 2}$ is glass transition temperature of polyamide [45].

As the energy $E$ is commonly considered to be low enough [22] so the preexponential term is included in $D_{02}$, Equation 10 can then be written as:

$$
D_{(T>T g)}=D_{02} \cdot \exp \left(-\frac{\gamma \cdot\left(w_{1} \cdot \hat{V}_{1}^{*}+\xi \cdot w_{2} \cdot \hat{V}_{2}^{*}\right)}{\hat{V}_{F H}}\right)
$$

The hole free volume can be calculated using Equation 12 from values for water as a solvent coming from the literature (see Table 1).

\begin{tabular}{|c|c|c|}
\hline Constant & Value & Reference \\
\hline$\hat{V}_{1}^{*}\left(\mathrm{~cm}^{3} / \mathrm{g}\right)$ & 1.071 & {$[46]$} \\
\hline$K_{11} / \gamma$ & $2.18 .10^{-3}$ & {$[46]$} \\
\hline$K_{21}-T_{g 1}$ & -152.3 & {$[46]$} \\
\hline
\end{tabular}

Table 1: Values for water as a solvent needed for the evaluation of the free volume

Other values needed for the evaluation of the free volume are related to the polymer and can be determined by the following equations using here again values from the literature and given in Table 2:

$$
\begin{gathered}
K_{22}=C_{2} \\
\frac{\gamma \cdot \hat{V}_{2}^{*}}{K_{12}}=2,303 \cdot C_{1} \cdot C_{2}
\end{gathered}
$$

Where $C_{1}$ and $C_{2}$ are the WLF constants for the polymer considered, here PA66. 


$$
\xi=\frac{V_{1}^{0}(0)}{V_{2}^{*}(j)}
$$

$V_{1}^{0}(0)$ is the molar volume of water and $V_{2}^{*}(j)$ is the molar volume of the polymer jumping unit that can be estimated according to [46]:

$$
V_{2}^{*}(j)=0,6224 \times T_{g}(K)-86,95
$$

where $T_{g}$ is the glass transition temperature of the dry polymer.

\begin{tabular}{|c|c|c|}
\hline Constant & Value & Reference \\
\hline$C_{1}$ & 17 & {$[47]$} \\
\hline$C_{2}$ & 51 & {$[47]$} \\
\hline$\hat{V}_{2}^{*}\left(\mathrm{~cm}^{3} / \mathrm{g}\right)$ & 0.935 & {$[47]$} \\
\hline
\end{tabular}

Table 2: Values related to the polymer needed for the evaluation of the free volume

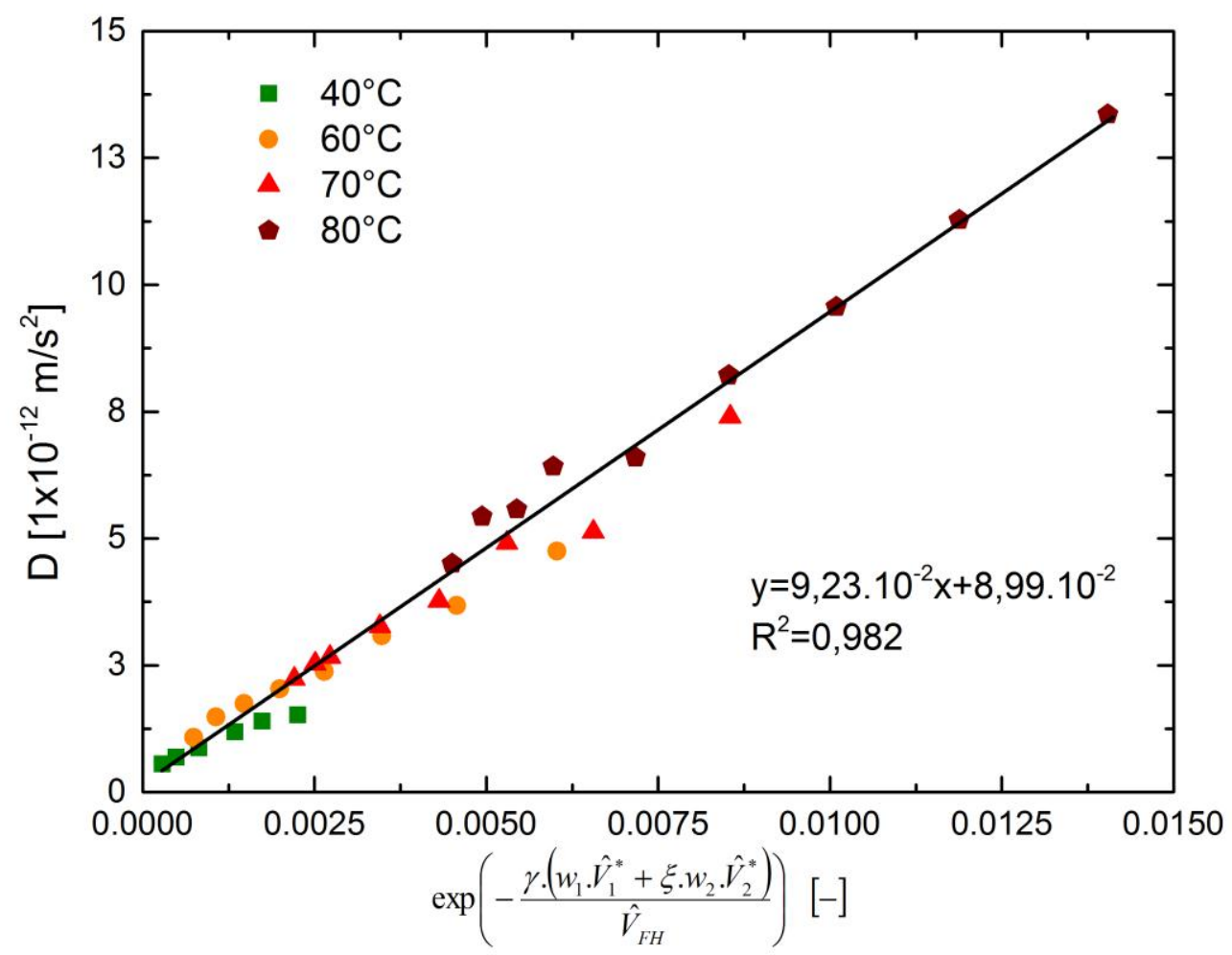

Figure 10: Validation of free volume theory in PA66 when in the rubbery state

Figure 10 plots the water diffusion coefficient variation versus the exponential term from Equation 12, for all the tested conditions when the polymer is in the rubbery state. $A$ common linear relationship can be observed for all the temperatures and water activities. This result means that in this case of PA66, the water diffusion can be described according to the free volume theory described above, with a value of $D_{02}$ equal to $1.1 \times 10^{-4} \mathrm{~m}^{2} / \mathrm{s}$. This value of $D_{02}$ is indeed the first evaluation performed on a wide database. Taking into account that this parameter is related to the interactions between the solvent and the polymer and depends on the molecular weights of the polymer and of the solvent, further investigations 
with varying molecular weights are needed in order to evaluate its physical meaning. It should be underlined that when the amorphous phase is in the rubbery state, the temperature dependence of water diffusivity is taken into account through the term $\hat{V}_{F H}$ that is dependent on $\left(\mathrm{T}-\mathrm{T}_{\mathrm{g}}\right)$ (see equation 11).

When the amorphous phase of PA66 is in the rubbery state, the water diffusion coefficient exhibits a complex behavior. Kinetics of water absorption depend both on the environment temperature and water activity. This complex dependence can be understood as the effect of a free volume formation in the polymer that is related to the difference between testing temperature and glass transition temperature of the polymer (that depends on water content). Moreover, it appears that, in this study, this complex behavior of water diffusivity can be described using theoretical considerations proposed by Vrentas [22].

\section{Conclusion}

Water diffusion in PA66 has been characterized in a wide range of temperature (from 25 to $80^{\circ} \mathrm{C}$ ) and water activity (from 0.05 to 0.9 ) using thin films. Moreover, the glass transition has been measured as a function of the water content in the polymer and it appears that the water sorption induces a sensitive drop of $\mathrm{T}_{\mathrm{g}}$ from $55^{\circ} \mathrm{C}$ in the dry state to lower than $0^{\circ} \mathrm{C}$ when water content is about $6 \%$. Due to this large $\mathrm{T}_{\mathrm{g}}$ variation, the amorphous phase of PA66 can actually shift from the glassy state to the rubbery state with the water uptake. When the amorphous phase is in a glassy state, the water diffusion coefficient depends only on temperature and this dependence can be described using an Arrhenius behavior with an activation energy of $20 \mathrm{~kJ} / \mathrm{mol}$. When the amorphous phase is in a rubbery state, the water diffusion coefficient depends both on the environment temperature and water activity. In this case, the dependency of the water diffusion coefficient on temperature and water activity can be described in a unified manner, using the free volume theory with a $D_{0}$ equal to $1.1 \times 10^{-4} \mathrm{~m}^{2} / \mathrm{s}$.

As a conclusion, this paper illustrates that knowing the environment parameters (i.e. temperature and water activity), it is possible to describe the diffusion coefficient. This approach includes the evaluation of the water uptake [42] then the prediction of $T_{g}$ using the Kelley-Bueche equation. The comparison of the environment temperature to the actual $\mathrm{T}_{\mathrm{g}}$ finally allows two cases to be distinguished. If PA66 is in the glassy state, the water diffusion coefficient is described using classical Arrhenius behavior. Whereas if the polymer is above $T_{g}$, the kinetics of water diffusion can be determined from free volume theory. 


\section{References}

[1] M. H. Cohen and D. Turnbull, Molecular Transport in Liquids and Glasses," J. Chem. Phys., vol. 31, no. 5, p. 1164, 1959.

[2] C. A. Kumins and T. K. Kwei, Free volume and other Theories," in Diffusion in polymers edited by J.Crank and G.S Park, 1968, p. 108.

[3] P. Moy and F. E. Karasz, Epoxy-water interactions," Polym. Eng. Sci., vol. 20, no. 4, pp. 315-319, 1980.

[4] I. Merdas, F. Thominette, A. Tcharkhtchi, and J. Verdu, Factors governing water absorption by composite matrices," Compos. Sci. Technol., vol. 62, no. 4, pp. 487-492, 2002.

[5] B. H. Zimm and J. L. Lundberg, Sorption of Vapors by High Polymers," J. Phys. Chem., vol. 60, no. 4, pp. 425-428, 1956.

[6] R. F. Fedors, Absorption of liquids by rubber vulcanizates," Polymer, vol. 20, no. 9, pp. 1087-1090, 1979.

[7] M. Sabard, F. Gouanvé, E. Espuche, R. Fulchiron, G. Seytre, L.-A. Fillot, and L. Trouillet-Fonti, Influence of film processing conditions on the morphology of polyamide 6: Consequences on water and ethanol sorption properties," J. Membr. Sci., vol. 415416, pp. 670-680, 2012.

[8] P. Y. Le Gac, G. Roux, P. Davies, B. Fayolle, and J. Verdu, Water clustering in polychloroprene," Polymer, vol. 55, no. 12, pp. 2861-2866, 2014.

[9] E. S. Gonçalves, L. Poulsen, and P. R. Ogilby, Mechanism of the temperaturedependent degradation of polyamide 66 films exposed to water," Polym. Degrad. Stab., vol. 92, no. 11, pp. 1977-1985, 2007.

[10] L.-T. Lim, I. J. Britt, and M. A. Tung, Sorption and transport of water vapor in nylon 6,6 film," J. Appl. Polym. Sci., vol. 71, no. 2, pp. 197-206, 1999.

[11] N. J. W. Reuvers, H. P. Huinink, H. R. Fischer, and O. C. G. Adan, Quantitative Water Uptake Study in Thin Nylon-6 Films with NMR Imaging," Macromolecules, vol. 45, no. 4, pp. 1937-1945, 2012.

[12] R. Puffr and J. Šebenda, - On the Structure and Properties of Polyamides. XXVII. The Mechanism of Water Sorption in Polyamides," J. Polym. Sci. Part C Polym. Symp., vol. 16, no. 1, pp. 79-93, 1967.

[13] L. Razumovskii, V. Markin, and G. Y. Zaikov, Sorption of water by aliphatic polyamides. Review," Polym. Sci. USSR, vol. 27, no. 4, pp. 751-768, 1985. 
[14] X. Colin and J. Verdu, Humid Ageing of Organic Matrix Composites," in Durability of Composites in a Marine Environment, vol. 208, P. Davies and Y. D. S. Rajapakse, Eds. Dordrecht: Springer Netherlands, 2014, pp. 47-114.

[15] C. El Mazry, Đurabilité de produits innovants de robinetterie en polyamide 6.6," Ecole Nationale Supérieure d'Arts et Métiers, Paris, 2013.

[16] H. K. Reimschuessel, Relationships on the effect of water on glass transition temperature and young's modulus of nylon 6," J. Polym. Sci. Polym. Chem. Ed., vol. 16, no. 6, pp. 1229-1236, 1978.

[17] M. Akay, Moisture absorption and its influence on the tensile properties of glass-fibre reinforced polyamide 6,6," Polym. Polym. Compos., vol. 2, no. 6, pp. 349-354, 1994.

[18] T. Alfrey, E. F. Gurnee, and W. G. Lloyd, Điffusion in glassy polymers," J. Polym. Sci. Part C Polym. Symp., vol. 12, no. 1, pp. 249-261, 1966.

[19] N. L. Thomas and A. H. Windle, A deformation model for Case II diffusion," Polymer, vol. 21, no. 6, pp. 613-619, 1980.

[20] Y.-M. Sun and H.-L. Lee, Sorption/desorption properties of water vapour in poly(2hydroxyethyl methacrylate): 1. Experimental and preliminary analysis," Polymer, vol. 37, no. 17, pp. 3915-3919, 1996.

[21] G. Dlubek, F. Redmann, and R. Krause-Rehberg, Humidity-induced plasticization and antiplasticization of polyamide 6: A positron lifetime study of the local free volume," $J$. Appl. Polym. Sci., vol. 84, no. 2, pp. 244-255, 2002.

[22] J. S. Vrentas and J. L. Duda, Diffusion in polymer-solvent systems. I. Reexamination of the free-volume theory," J. Polym. Sci. Polym. Phys. Ed., vol. 15, no. 3, pp. 403-416, 1977.

[23] B. Jacques, M. Werth, I. Merdas, F. Thominette, and J. Verdu, Hydrolytic ageing of polyamide 11. 1. Hydrolysis kinetics in water," Polymer, vol. 43, no. 24, pp. 6439-6447, 2002.

[24] J. L. Thomason, Structure-property relationships in glass-reinforced polyamide, Part 3: Effects of hydrolysis ageing on the dimensional stability and performance of short glass-fiber-reinforced polyamide 66," Polym. Compos., vol. 28, no. 3, pp. 344-354, 2007.

[25] E. Lissi, Entropic control of chemiluminescent reactions," J. Am. Chem. Soc., vol. 98, no. 11, pp. 3386-3387, 1976.

[26] N. Chaupart, G. Serpe, and J. Verdu, Aolecular weight distribution and mass changes during polyamide hydrolysis," Polymer, vol. 39, no. 6-7, pp. 1375-1380, 1998.

[27] D. Garcia and H. W. Starkweather, Hydrogen bonding in nylon 66 and model compounds," J. Polym. Sci. Polym. Phys. Ed., vol. 23, no. 3, pp. 537-555, 1985.

[28] M. H. Cohen and G. S. Grest, tiquid-glass transition, a free-volume approach," Phys. Rev. B, vol. 20, no. 3, pp. 1077-1098, 1979.

[29] V. M. Litvinov and J. P. Penning, Phase Composition and Molecular Mobility in Nylon 6 Fibers as Studied by Proton NMR Transverse Magnetization Relaxation," Macromol. Chem. Phys., vol. 205, no. 13, pp. 1721-1734, 2004.

[30] N. Reuvers, H. Huinink, and O. Adan, Water Plasticizes Only a Small Part of the Amorphous Phase in Nylon-6," Macromol. Rapid Commun., vol. 34, no. 11, pp. 949953, 2013.

[31] J. Crank, The Mathematics Diffusion. Oxford University Press, 1979.

[32] J. Crank and G. S. Park, Diffusion in Polymers. Academic Press Inc, 1968.

[33] J. Comyn, Polymer Permeability. Springer, 1985.

[34] E. Gaudichet-Maurin, Garactérisation et vieillissement d'une membrane d'ultrafiltration d'eau," Arts et Métiers ParisTech, 2005.

[35] M. Broudin, V. Le Saux, P. Y. Le Gac, C. Champy, G. Robert, P. Charrier, and Y. Marco, Moisture sorption in polyamide 6.6: Experimental investigation and comparison to four physical-based models," Polym. Test., vol. 43, pp. 10-20, 2015.

[36] A. Launay, Y. Marco, M. H. Maitournam, and I. Raoult, Modelling the influence of temperature and relative humidity on the time-dependent mechanical behaviour of a short glass fibre reinforced polyamide," Mech. Mater., vol. 56, pp. 1-10, 2013. 
[37] S.-W. Wong and K. C. Frisch, Studies of catalysed isocyanate reactions by high performance liquid chromatography," Prog. Rubber Plast. Technol., vol. 7, no. 3, pp. 243-270, 1991.

[38] C. Maggana and P. Pissis, Water sorption and diffusion studies in an epoxy resin system," J. Polym. Sci. Part B Polym. Phys., vol. 37, no. 11, pp. 1165-1182, 1999.

[39] O. Rodr guez, F. Fornasiero, A. Arce, C. Radke, and J.-M. Prausnitz, Solubilities and diffusivities of water vapor in poly(methylmethacrylate), poly(2hydroxyethylmethacrylate), poly(N-vinyl-2-pyrrolidone) and poly(acrylonitrile)," Polymer, vol. 44, no. 20, pp. 6323-6333, 2003.

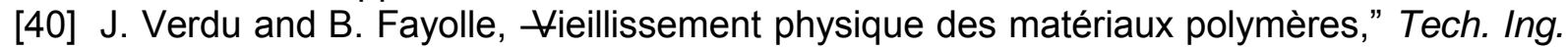
Propr. Générales Plast., vol. base documentaire : TIB152DUO., no. ref. article : am3150, 2005.

[41] O. Starkova, S. T. Buschhorn, E. Mannov, K. Schulte, and A. Aniskevich, Water transport in epoxy/MWCNT composites," Eur. Polym. J., vol. 49, no. 8, pp. 2138-2148, 2013.

[42] P. Y. Le Gac, D. Choqueuse, and D. Melot, - Pescription and modeling of polyurethane hydrolysis used as thermal insulation in oil offshore conditions," Polym. Test., vol. 32, no. 8, pp. 1588-1593, 2013.

[43] L. Silva, S. Tognana, and W. Salgueiro, Study of the water absorption and its influence on the Young's modulus in a commercial polyamide," Polym. Test., vol. 32, no. 1, pp. 158-164, 2013.

[44] J. S. Vrentas and J. L. Duda, Diffusion in polymer-solvent systems. II. A predictive theory for the dependence of diffusion coefficients on temperature, concentration, and molecular weight," J. Polym. Sci. Polym. Phys. Ed., vol. 15, no. 3, pp. 417-439, 1977.

[45] J. S. Vrentas and J. L. Duda, A free-volume interpretation of the influence of the glass transition on diffusion in amorphous polymers," J. Appl. Polym. Sci., vol. 22, no. 8, pp. 2325-2339, 1978.

[46] S.-U. Hong, Prediction of Polymer/Solvent Diffusion Behavior Using Free-Volume Theory," Ind. Eng. Chem. Res., vol. 34, no. 7, pp. 2536-2544, 1995.

[47] D. W. van Krevelen and K. te Nijenhuis, Properties of Polymers: Their Correlation with Chemical Structure; their Numerical Estimation and Prediction from Additive Group Contributions. Elsevier, 2009. 